\title{
Clinical Outcomes After Femtosecond Laser-Assisted Arcuate Corneal Incisions versus Manual Incisions
}

\author{
Clayton Blehm (1D) \\ Richard Potvin (iD) ${ }^{2}$ \\ 'Gainesville Eye Associates, Gainesville, \\ GA, USA; ${ }^{2}$ Science in Vision, Bend, \\ OR, USA
}

Purpose: To compare the relative effectiveness of Verion-LenSx guided femtosecond arcuate incisions and manual incisions in reducing postoperative refractive astigmatism.

Patients and Methods: This was a contralateral eye, prospective study that included subjects with $0.50 \mathrm{D}$ to $1.75 \mathrm{D}$ of corneal astigmatism who wanted less refractive astigmatism post cataract surgery. The surgeon used anterior keratometry and the Woodcock astigmatism nomogram for preoperative planning, while the LenSx femtosecond laser with the Verion Image Guided System was used to create all laser arcuate incisions. Manual incisions were planned using the Donnenfeld nomogram and made with a fixed-depth diamond knife. The primary outcome measure was the residual refractive astigmatism at 3 months postoperative. Secondary outcome measures included the manifest refraction, uncorrected distance visual acuity and the change in corneal astigmatism from 1 to 3 months postoperative.

Results: Forty-one subjects were successfully enrolled in the study, with data from 38 subjects available at 3 months. There were no statistically significant differences in refractive astigmatism, corneal astigmatism, uncorrected distance visual acuity or manifest refraction between the Manual and Femto groups at either 1 month or 3 months. Significant changes in refractive and corneal astigmatism were noted between 1 months and 3 months. Ninety percent of eyes in both groups had $\leq 0.50 \mathrm{D}$ of refractive astigmatism at 3 months. Two minor non-serious adverse events (full-thickness incisions of the cornea) occurred in two eyes of two different subjects in the Manual group; they were resolved without incident. Conclusion: Laser arcuate incisions appear to be an effective means of reducing postoperative refractive astigmatism at the time of cataract surgery. No significant clinical differences were observed between incisions made manually and those made with an imageguided femto-second laser system. The lower number of minor adverse events experienced with the femtosecond laser system is an apparent advantage.

Keywords: Verion, LenSx, cylinder, femtosecond, cataract surgery, corneal arcuate incisions, astigmatism

\section{Plain Language Summary}

Many patients having cataract surgery have low levels of astigmatism, an optical error that causes blurred vision at all viewing distances. Low levels of astigmatism may be treated at the time of surgery by making partial thickness incisions in the cornea, the clear front part of the eye. Traditionally, this has been performed manually, with a small blade held by the surgeon. More recently, a new technology that involves the use of a laser to make the incision has become available. Imaging systems help guide the placement and depth of the laser incision. 
This study was designed to see if there were clinical advantages to using the laser system. The relative effect of both the manual and laser incisions appeared similar 3 months after surgery. The laser system was associated with fewer complications at the time of surgery. It may therefore be a recommended alternative to a manual technique.

\section{Introduction}

The presence of a low to moderate level of corneal astigmatism at the time of cataract surgery is very common. It is estimated that two-thirds of eyes presenting for cataract surgery will have between $0.50 \mathrm{D}$ and $1.50 \mathrm{D}$ of corneal astigmatism. ${ }^{1}$ With a non-toric intraocular lens (IOL), such levels of corneal astigmatism may contribute to a level of refractive astigmatism that is likely to compromise uncorrected vision. ${ }^{2}$

The primary surgical options for reducing astigmatism at the time of cataract surgery include implantation of a toric IOL or the use of corneal arcuate incisions to alter the topography of the cornea. The decision of which method to use may be affected by IOL availability, cost considerations and the magnitude of the corneal astigmatism measured. The two methods appear to provide similar clinical outcomes and visual quality at low levels of astigmatism, ${ }^{3-5}$ but at higher levels of corneal astigmatism (ie, $>1.50 \mathrm{D}$ ) toric IOLs appear to be more effective and predictable. ${ }^{6}$ Corneal relaxing incisions have traditionally been created manually, using a hand-held blade. This increases the level of surgical skill required for cataract surgery. By contrast, implanting a toric IOL is little different than implanting a non-toric IOL, with the exception of requiring more precise orientation in the bag.

Recently, femtosecond laser systems with image guidance capability have been developed for use during cataract surgery. While primarily developed to assist with lens fragmentation and creation of the capsulorhexis, they can also be used to create corneal arcuate incisions. With such a laser system, the location, depth and extent of the incisions can be more precisely controlled, and the measurement of the anterior and posterior corneal positions can prevent inadvertent full-thickness perforation. In addition, associated image guidance systems can improve alignment of the incision; ${ }^{7}$ if the image guidance system registers corneal astigmatism in the upright state, compensation for cyclotorsion is possible when the laser is used in the supine position. These features are likely to improve the predictability, safety and effectiveness of any astigmatism correction. Laser arcuate incisions have been demonstrated to significantly reduce corneal astigmatism. ${ }^{8,9}$

The purpose of this study was to compare the relative effectiveness of corneal arcuate incisions made with a manual (blade) technique to those planned using an image guided system and created using a femtosecond laser system (Verion ${ }^{\circledR}$ Image Guided System, and LenSx ${ }^{\circledR}$, both Alcon, Fort Worth, USA). We know of no other contralateral comparison of these two methods (manual vs femtosecond laser system) in the literature.

\section{Patients and Methods}

This study was a comparative, prospective, randomized contralateral eye study of visual outcomes after corneal arcuate incisions at the time of cataract surgery. Subjects had to be presenting for cataract surgery with $0.50 \mathrm{D}$ to $1.75 \mathrm{D}$ of regular corneal astigmatism, good ocular health, a potential acuity of $20 / 25$ or better and be scheduled to have a non-toric monofocal IOL (SN60WF, Alcon, Fort Worth, USA) implanted in both eyes. Subjects with irregular astigmatism, previous ocular surgery or an ocular/ medical history that was likely to confound the results of the investigation (eg, diabetes, atopic disease) were excluded.

The sample size was calculated based on an expected difference of $0.25 \mathrm{D}$ in refractive astigmatism, a power of 0.8 and an alpha ( $\mathrm{p}$ value) of 0.05 . The standard deviation of postoperative refractive astigmatism was estimated to be $0.4 \mathrm{D}$. With these values, it was determined that 41 contralateral subjects would be required. The study was approved by an institutional review board (SALUS IRB, Austin, TX) and was registered with clinicaltrials.gov (NCT04126174). All subjects signed an IRB-approved informed consent document, and the study was conducted in a manner consistent with the tenets of the Declaration of Helsinki and local regulatory requirements.

Biometry was measured with the Lenstar LS900 (Haag-Streit, Kõniz, Switzerland), with corneal keratometry checked with the Atlas 9000 topographer (Carl Zeiss Meditec, Berlin, Germany). Ultrasound pachymetry was measured on all eyes receiving a manual incision. One randomly chosen eye of each subject was treated using a fixed keratome diamond knife set for 500-600 microns to create the incisions, with an $8.0 \mathrm{~mm}$ optical zone and the incision arc length based on the Donnenfeld nomogram (Manual group). The contralateral eye (Femto group) received arcuate relaxing incisions planned using the Woodcock nomogram ${ }^{10}$ and administered with the 
LenSx femtosecond laser system, with standard settings of an $8.0 \mathrm{~mm}$ optical zone and $90 \%$ incision depth. All Femto incisions were opened. The Verion ${ }^{\circledR}$ Image Guided System was used to register the orientation of the eye for the femtosecond laser incisions. The surgeon completed surgery using an all-manual technique (ie, no femto capsulotomy, lens fragmentation or surgical incisions).

Subject visits included a preoperative evaluation, a surgery visit and 1-day postoperative visit for each eye, and follow-up visits 1 month and 3 months after the second eye surgery. Clinical evaluations included measurement of visual acuity, manifest refraction, corneal astigmatism (measured postoperatively with the Lenstar device) and a standard slit-lamp examination. Any adverse events/serious adverse events (AEs/SAEs) were recorded at the operative visit and at all postoperative visits.

The primary outcome measure of interest was the residual refractive astigmatism. Secondary measures of interest included the percentage of eyes with $\leq 0.50$ D of refractive astigmatism, the uncorrected monocular distance visual acuity (UDVA), corneal astigmatism and the manifest refraction. Statistical testing included analysis of variance (ANOVA) for continuous variables and appropriate non-parametric tests for categorical data, with significance set at $p=0.05$. Between-eye results (by subject) were compared using a repeatedmeasures ANOVA. Astigmatism analyses were performed using vector math. Data are not available for sharing.

\section{Results}

Forty-one subjects were successfully enrolled in the study. Three subjects were lost to follow-up, leaving 38 subjects with data available at 3 months; of these, four subjects did not attend their 1-month visit.

Demographic and preoperative keratometry data for subjects completing the study are shown in Table 1 . In several instances, reliable anterior cornea measurements could not be made on all devices, but at least 35 eyes could be measured for all groups/devices. There was no difference in the mean keratometry or the corneal astigmatism measured by device between groups, indicating a good match (as expected, with contralateral eyes). There were statistically significant differences in the mean keratometry and corneal astigmatism measured between devices in some cases; these are identified in the table. A repeated measures ANOVA with a Tukey's Honestly Significant Difference post-hoc test was used to determine which devices differed.

The distribution of postoperative refractive astigmatism by treatment device is shown in Figure 1 (1 month) and Figure 2 ( 3 months). Table 2 summarizes the relevant refractive and keratometric data at 1 month and 3 months postoperative. Corneal astigmatism data are reported based on measurements obtained with the Lenstar device. There were no statistically significant differences in the measured variables between the Manual and Femto groups at either 1 month or 3 months. Residual refractive astigmatism was statistically significantly lower at 3 months than at 1 month for both groups, with a slightly larger improvement in the Manual group $(p=0.002)$. Corneal astigmatism in

Table I Demographics and Corneal Cylinder Data $(\mathrm{n}=38$ Subjects, 76 Eyes)

\begin{tabular}{|c|c|c|c|}
\hline Age (Years) & $69 \pm 7(51$ to 83$)$ & & \\
\hline Female/Male & $21 / 17$ & & \\
\hline Mean Keratometry (D) & Manual & Femto & $P$ \\
\hline Lenstar & $44.07 \pm 1.18$ (4I.40 to 46.65$)$ & $44.11 \pm 1.25(41.95$ to 46.40$)$ & 0.90 \\
\hline Verion & $44.51 \pm 1.21$ (4I.72 to 47.29$)$ & $44.59 \pm 1.29(42.13$ to 47.11$)$ & 0.80 \\
\hline Topography & $43.83 \pm 1.31$ (40.15 to 46.06$)$ & $44.04 \pm 1.15(42.01$ to 46.42$)$ & 0.47 \\
\hline $\mathrm{P}$ & $0.00 *$ & $0.00 *$ & \\
\hline Corneal astigmatism (D) & Manual & Femto & $\mathrm{P}$ \\
\hline Lenstar & $0.98 \pm 0.39$ (0.22 to 1.89$)$ & $1.05 \pm 0.33(0.48$ to $1.6 \mathrm{I})$ & 0.46 \\
\hline Verion & $1.03 \pm 0.53(0.00$ to 2.50$)$ & $1.04 \pm 0.45(0.22$ to 1.80$)$ & 0.92 \\
\hline Topography & $0.85 \pm 0.46(0.11$ to 1.88$)$ & $0.93 \pm 0.5 \mathrm{I}(0.15$ to 2.25$)$ & 0.47 \\
\hline $\mathrm{P}$ & $0.03 * *$ & 0.37 & \\
\hline
\end{tabular}

Notes: *Repeated measures ANOVA, Verion results different from Lenstar and Topography. **Repeated measures ANOVA, Verion and Topography results different. 


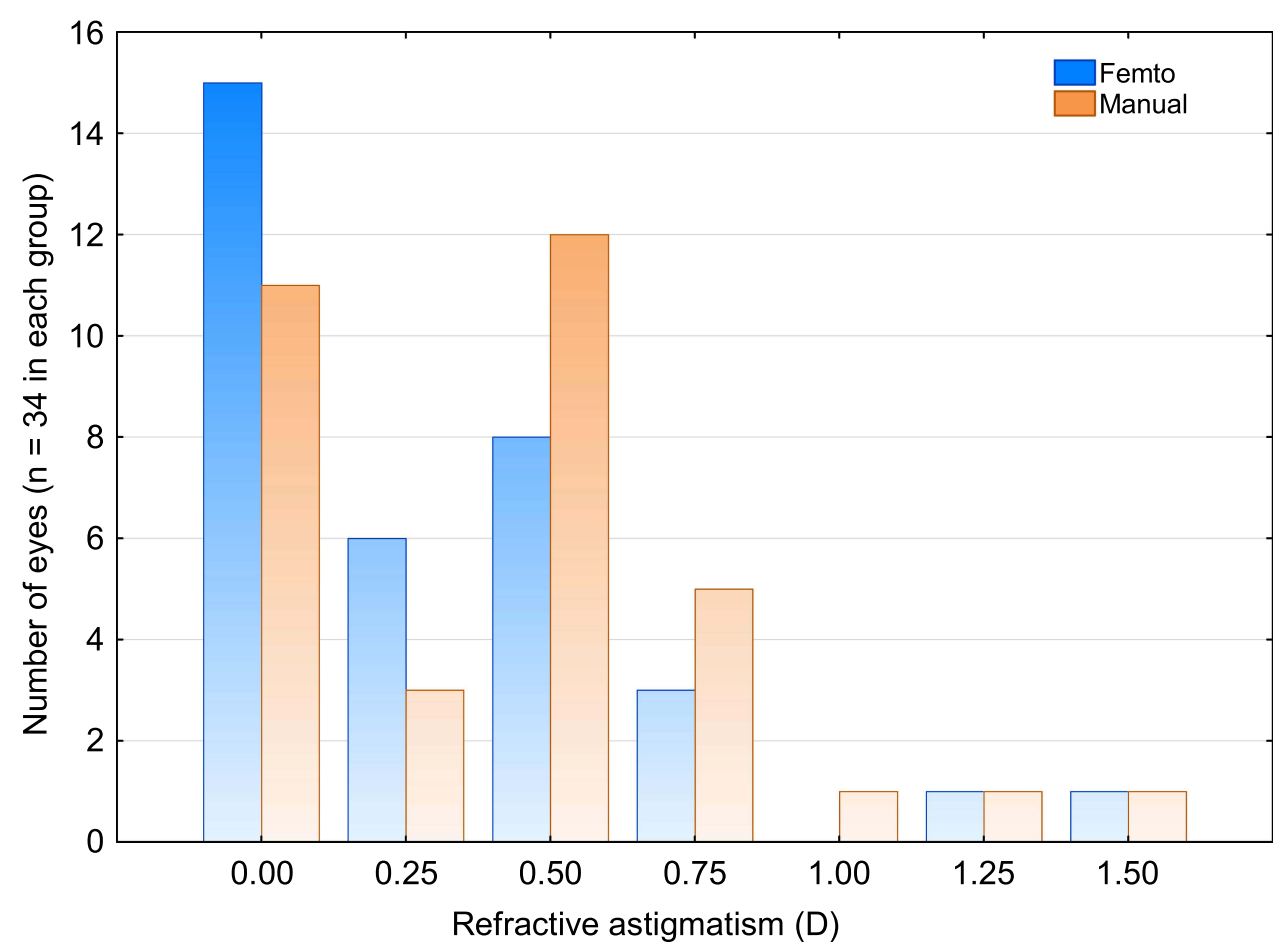

Figure I Distribution of refractive astigmatism I month postoperative by treatment method. Abbreviation: D, diopter.

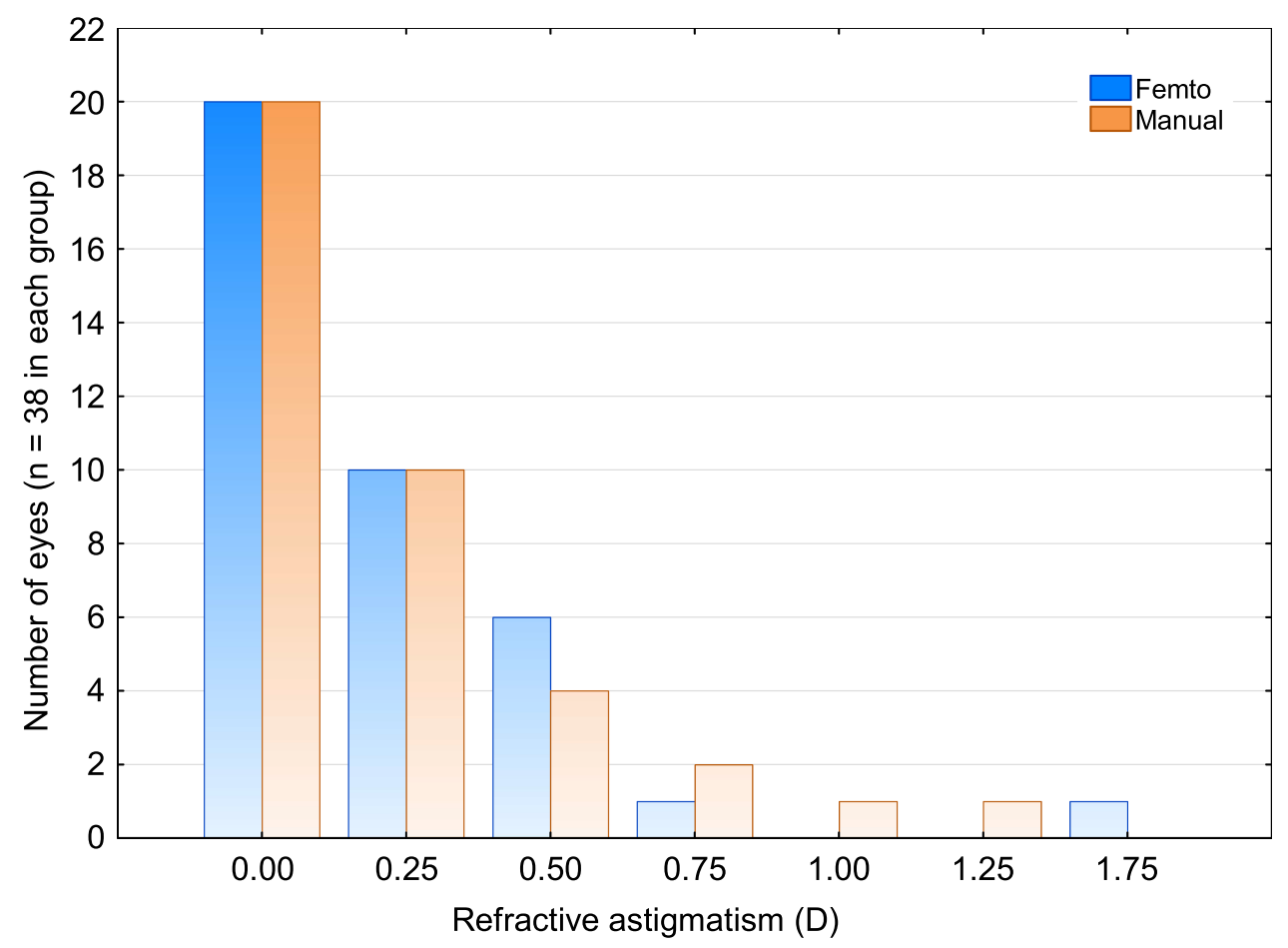

Figure 2 Distribution of refractive astigmatism 3 months postoperative by treatment method. Abbreviation: D, diopter. 
Table 2 Summary Refractive and Keratometric Data (Statistical Test of Changes from IM to 3M Were Restricted to Eyes with Data at Both Time Points)

\begin{tabular}{|c|c|c|c|c|}
\hline & & I Month & 3 Months & $\mathbf{p}$ \\
\hline \multirow[t]{3}{*}{ Refractive astigmatism (D) } & Manual & $0.42 \pm 0.38(0.00$ to 1.50$)$ & $0.22 \pm 0.31$ ( 0.00 to 1.25$)$ & 0.002 \\
\hline & Femto & $0.31 \pm 0.37(0.00$ to 1.50$)$ & $0.21 \pm 0.33(0.00$ to 1.75$)$ & 0.03 \\
\hline & $P$ & 0.23 & 0.93 & \\
\hline \multirow[t]{3}{*}{ Eyes with $\leq 0.50 \mathrm{D}$ of refractive astigmatism* } & Manual & $26 / 34(76 \%)$ & $34 / 38(89 \%)$ & 0.14 \\
\hline & Femto & $29 / 34(85 \%)$ & $36 / 38(95 \%)$ & 0.18 \\
\hline & $P$ & 0.35 & 0.39 & \\
\hline \multirow[t]{3}{*}{ Mean refraction spherical equivalent (D) } & Manual & $0.00 \pm 0.38(-1.00$ to +0.75$)$ & $0.00 \pm 0.27(-0.63$ to +0.38$)$ & 0.88 \\
\hline & Femto & $-0.04 \pm 0.47(-2.25$ to 0.50$)$ & $-0.02 \pm 0.37(-1.38$ to 0.63$)$ & 0.41 \\
\hline & $P$ & 0.64 & 0.83 & \\
\hline \multirow[t]{3}{*}{ Corneal astigmatism from Lenstar (D) } & Manual & $0.89 \pm 0.53(0.00$ to 2.34$)$ & $0.70 \pm 0.40$ (0.00 to 1.59$)$ & 0.05 \\
\hline & Femto & $0.75 \pm 0.4 \mathrm{I}(0.00$ to $2.1 \mathrm{I})$ & $0.63 \pm 0.34$ (0.08 to 1.54$)$ & 0.09 \\
\hline & $P$ & 0.23 & 0.44 & \\
\hline Magnitude of vector change $(D)$ in corneal astigmatism (IM & Manual & \multicolumn{3}{|c|}{$0.65 \pm 0.40(0.17$ to 1.61$)$} \\
\hline to $3 \mathrm{M}$ ), from the Lenstar biometer & Femto & \multicolumn{3}{|c|}{$0.55 \pm 0.39(0.05$ to 1.41$)$} \\
\hline & $\mathrm{P}$ & \multicolumn{3}{|c|}{0.29} \\
\hline \multirow[t]{3}{*}{ Uncorrected distance visual acuity (logMAR) } & Manual & $0.11 \pm 0.13(0.00$ to 0.60$)$ & $0.08 \pm 0.10(0.00$ to 0.40$)$ & 0.10 \\
\hline & Femto & $0.10 \pm 0.12(0.00$ to 0.60$)$ & $0.10 \pm 0.12(0.00$ to 0.50$)$ & 0.56 \\
\hline & $p$ & 0.59 & 0.64 & \\
\hline
\end{tabular}

Note: *Compared using the Chi-squared test.

Abbreviations: D, diopter; logMAR, log of the minimum angle of resolution.

the Manual group was also statistically significantly lower at the 3-month visit relative to the 1 month visit $(p=0.05)$.

There were two minor non-serious adverse events at the time of surgery, both in the Manual group. Fullthickness incisions of the cornea occurred in two eyes of two different subjects. Both were sutured closed with no further incident and no long-term effect on visual acuity. Sutures were removed at least 2 weeks prior to the 1-month visit in both cases.

\section{Discussion}

The current study compared visual outcomes between corneal arcuate incisions made manually with a blade to those made with a femtosecond laser system, with treatment assigned to contralateral eyes. As noted in the results, there was no statistically significant difference between the groups with regard to refractive astigmatism at 3 months postoperative. There was, however, a statistically significant reduction in refractive astigmatism from 1 month to 3 months in both groups. This emphasizes the need for a minimum follow-up of 3 months when evaluating corneal arcuate incisions for the correction of astigmatism. An earlier study of corneal incisions by the same authors reached the same conclusion. ${ }^{10}$

The mean differences in measured preoperative keratometry were relatively small, but statistically significant in many cases. While some previous studies have noted no difference between devices measuring anterior keratometry and consider them interchangeable, ${ }^{11}$ others have reported good correlation but large limits of agreement, suggesting that devices should not be used interchangeably. ${ }^{12,13}$ The data here supports the latter recommendation.

At 3 months postoperative, more than half the eyes in each group had no refractive astigmatism, while around $90 \%$ had $\leq 0.50 \mathrm{D}$. These results, for both the Manual and Femto groups, are better than has been reported in several recent studies. ${ }^{14-16}$ In the study by Stanojcic et al, the authors reported no significant differences between the results of manual and femtosecond laser incisions, consistent with the findings in the current study. ${ }^{14}$ This suggests that the increased locational accuracy and precision of the femtosecond laser incisions is not a limiting factor - it may be that preoperative measurement and surgical planning must be improved before the perceived benefits of 
image-guided laser use are fully realized. ${ }^{17}$ Dry eye is a well-recognized factor in limiting the accuracy of preoperative diagnostic measurements. ${ }^{18,19}$

The mean UDVA of $\sim 0.10 \log$ MAR at 3 months postoperative was similar to, or slightly better than, previously reported results. ${ }^{5,8,14-16,20}$ This appears consistent with the lower amounts of residual refractive astigmatism reported in the current study and the fact that the mean spherical equivalent refraction was very close to plano.

There are limitations to the current study. The number of subjects was relatively low, sufficient to allow betweengroup analysis but not to provide reliable subgroup analysis, such as evaluating outcomes by orientation of the preoperative corneal astigmatism. In addition, arcuate incision planning was based only on anterior corneal keratometry measurements; research suggests that incorporating measured or estimated posterior corneal measurement may be helpful in better correcting total corneal astigmatism. ${ }^{17}$ Finally, results were based on older nomograms - the Donnenfeld and Woodcock nomograms have been in use for $10+$ years and are relatively simple. It is possible that more recent, advanced nomograms/formulas could further improve mean results or reduce outcome variability. ${ }^{15,21}$

In conclusion, laser arcuate incisions appear to be an effective means of reducing postoperative refractive astigmatism at the time of cataract surgery. No significant clinical differences were observed between incisions made manually and those made with an image-guided femto-second laser system. The lower number of minor adverse events experienced with the femtosecond laser system is an apparent advantage.

\section{Acknowledgments}

Brad Hall, $\mathrm{PhD}$, of Sengi Data, assisted in the preparation of this manuscript. This research was conducted with support from Alcon, in the form of an investigator-initiated study grant (IIT \# 50130883).

\section{Disclosure}

Richard Potvin is a consultant to Alcon and Carl Zeiss Meditec. The authors report no other conflicts of interest in this work.

\section{References}

1. Hoffmann PC, Hütz WW. Analysis of biometry and prevalence data for corneal astigmatism in 23,239 eyes. $J$ Cataract Refract Surg. 2010;36(9):1479-1485. PMID: 20692558. doi:10.1016/j.jcrs.2010. 02.025
2. Atchison DA, Mathur A. Visual acuity with astigmatic blur. Optom Vis Sci. 2011;88(7):E798-805. PMID: 21478784. doi:10.1097/ OPX.0b013e3182186bc4

3. Mingo-Botín D, Muñoz-Negrete FJ, Won Kim HR, Morcillo-Laiz R, Rebolleda G, Oblanca N. Comparison of toric intraocular lenses and peripheral corneal relaxing incisions to treat astigmatism during cataract surgery. J Cataract Refract Surg. 2010;36(10):1700-1708. PMID: 20870116. doi:10.1016/j.jcrs.2010.04.043

4. Lake JC, Victor G, Clare G, Porfírio GJ, Kernohan A, Evans JR. Toric intraocular lens versus limbal relaxing incisions for corneal astigmatism after phacoemulsification. Cochrane Database Syst Rev. 2019;12(12):CD012801. PMID: 31845757; PMCID: PMC6916141. doi:10.1002/14651858.CD012801.pub2

5. Leon P, Pastore MR, Zanei A, et al. Correction of low corneal astigmatism in cataract surgery. Int $J$ Ophthalmol. 2015;8 (4):719-724. PMID: 26309869; PMCID: PMC4539655. doi:10.3980/j.issn.2222-3959.2015.04.14

6. Roberts TV, Sharwood P, Hodge C, Roberts K, Sutton G. Comparison of toric intraocular lenses and arcuate corneal relaxing incisions to correct moderate to high astigmatism in cataract surgery. Asia Pac $J$ Ophthalmol (Phila). 2014;3(1):9-16. PMID: 26107301. doi:10.1097/APO.0b013e3182a0af21

7. Grewal DS, Basti S. Comparison of morphologic features of clear corneal incisions created with a femtosecond laser or a keratome. $J$ Cataract Refract Surg. 2014;40(4):521-530. PMID: 24568722. doi:10.1016/j.jcrs.2013.11.028

8. Visco DM, Bedi R, Packer M. Femtosecond laser-assisted arcuate keratotomy at the time of cataract surgery for the management of preexisting astigmatism. $J$ Cataract Refract Surg. 2019;45 (12):1762-1769. Erratum in: J Cataract Refract Surg. 2020 Apr;46(4):658.PMID: 31856987. doi:10.1016/j.jcrs.2019.08.002

9. Schwarzenbacher L, Schartmüller D, Röggla V, Meyer E, Leydolt C, Menapace R. One-year results of arcuate keratotomy in patients with low to moderate corneal astigmatism using a low-pulse-energy femtosecond laser. Am $J$ Ophthalmol. 2020;224:53-65. PMID: 33309694. doi:10.1016/j.ajo.2020.11.018

10. Blehm C, Potvin R. Pseudophakic astigmatism reduction with femtosecond laser-assisted corneal arcuate incisions: a pilot study. Clin Ophthalmol. 2017;11:201-207. PMID: 28176960; PMCID: PMC5271394. doi:10.2147/OPTH.S127279

11. Lauschke JL, Lawless M, Sutton G, Roberts TV, Hodge C. Assessment of corneal curvature using verion optical imaging system: a comparative study. Clin Exp Ophthalmol. 2016;44 (5):369-376. PMID: 27381574. doi:10.1111/ceo.12687

12. Mueller A, Thomas BC, Auffarth GU, Holzer MP. Comparison of a new image-guided system versus partial coherence interferometry, Scheimpflug imaging, and optical low-coherence reflectometry devices: keratometry and repeatability. $J$ Cataract Refract Surg. 2016;42(5):672-678. PMID: 27255242. doi:10.1016/j.jcrs.2016.01.042

13. Asena L, Güngör SG, Akman A. Comparison of keratometric measurements obtained by the Verion Image Guided System with optical biometry and auto-keratorefractometer. Int Ophthalmol. 2017;37 (2):391-399. PMID: 27271763. doi:10.1007/s10792-016-0274-8

14. Stanojcic N, Roberts HW, Wagh VK, Li JO, Naderi K, O'Brart DP. A randomised controlled trial comparing femtosecond laser-assisted cataract surgery versus conventional phacoemulsification surgery: 12-month results. Br J Ophthalmol. 2020. bjophthalmol-2020316311. PMID: 32699049. doi:10.1136/bjophthalmol-2020-316311

15. Wendelstein JA, Hoffmann PC, Mariacher S, et al. Precision and refractive predictability of a new nomogram for femtosecond laser-assisted corneal arcuate incisions. Acta Ophthalmol. 2021. PMID: 33629542. doi:10.1111/aos.14837

16. Yoo A, Yun S, Kim JY, Kim MJ, Tchah H. Femtosecond laser-assisted arcuate keratotomy versus toric IOL implantation for correcting astigmatism. $J$ Refract Surg. 2015;31(9):574-578. doi:10.3928/1081597X-20150820-01 
17. Zheng T, Chen Z, Lu Y. Influence factors of estimation errors for total corneal astigmatism using keratometric astigmatism in patients before cataract surgery. J Cataract Refract Surg. 2016;42(1):84-94. PMID: 26948782. doi:10.1016/j.jcrs.2015.07.037

18. Epitropoulos AT, Matossian C, Berdy GJ, Malhotra RP, Potvin R. Effect of tear osmolarity on repeatability of keratometry for cataract surgery planning. J Cataract Refract Surg. 2015;41(8):1672-1677. PMID: 26432124. doi:10.1016/j.jcrs.2015.01.016

19. Chuang J, Shih KC, Chan TC, Wan KH, Jhanji V, Tong L. Preoperative optimization of ocular surface disease before cataract surgery. J Cataract Refract Surg. 2017;43(12):1596-1607. PMID: 29335106. doi:10.1016/j.jcrs.2017.10.033
20. Ganesh S, Brar S, Reddy Arra R. Comparison of astigmatism correction between anterior penetrating and intrastromal arcuate incisions in eyes undergoing femtosecond laser-assisted cataract surgery. J Cataract Refract Surg. 2020;46(3):394-402. PMID: 32050207. doi:10.1097/j.jcrs.0000000000000069

21. Wortz G, Gupta PK, Goernert P, et al. Outcomes of femtosecond laser arcuate incisions in the treatment of low corneal astigmatism. Clin Ophthalmol. 2020;14:2229-2236. PMID: 32982147; PMCID: PMC7500082. doi:10.2147/OPTH.S264370
Clinical Ophthalmology

\section{Publish your work in this journal}

Clinical Ophthalmology is an international, peer-reviewed journal covering all subspecialties within ophthalmology. Key topics include: Optometry; Visual science; Pharmacology and drug therapy in eye diseases; Basic Sciences; Primary and Secondary eye care; Patient Safety and Quality of Care Improvements. This journal is indexed on PubMed

Submit your manuscript here: https://www.dovepress.com/clinical-ophthalmology-journal
Dovepress

Central and CAS, and is the official journal of The Society of Clinical Ophthalmology (SCO). The manuscript management system is completely online and includes a very quick and fair peer-review system, which is all easy to use. Visit http://www.dovepress.com/ testimonials.php to read real quotes from published authors. 